\title{
How to Write Geography Teaching Paper
}

\author{
Hua Liu (Corresponding author) \\ Physics Science \& Technology School, Zhanjiang Normal College \\ Zhanjiang 524048, China \\ Tel: 86-10-759-3183046_E-mail: liuhua-5@163.com \\ $\mathrm{Lu} \mathrm{Li}$ \\ Physics Science \& Technology School, Zhanjiang Normal College \\ Zhanjiang 524048, China
}

The Department of Geography and Resource Management, the Chinese University of Hong Kong

\begin{abstract}
Geography teaching paper is the paper especially to describe geography teaching reform and research achievement, its main purpose is to find solution to handle questions encountered in teaching through personal teaching practice, constant trying and exploration, and to scientifically summarize the procedure and methods to deal with the problem, rethink and sublimate them, to promote and communicate them in subject teaching and researching.
\end{abstract}

Keywords: Geography, Teaching, Paper, Writing

Geography teaching paper is the article especially to describe the achievement of geography teaching and researching. The content of geography teaching paper is broad, from the achievement of subject researching to the experience and feeling of one lesson. The main purpose of teaching geography is to find solution to handle questions encountered in teaching through personal teaching practice, constant trying and exploration, and to scientifically summarize the procedure and methods to deal with the problem, rethink and sublimate them, to promote and communicate them in subject teaching and researching.

\section{How to write the task of the paper: the question is the task}

When choosing the task of paper, firstly we should consider its value to choose the task that has scientific value objectively. The value of the task reflects in practical use of regular teaching, therefore, "the question is the task." When choosing the task of teaching paper, teachers should base on their own teaching reality, intensively thinking and exploring those questions and confusions encountered in teaching, choosing the best breakthrough point of research.

Besides, we should choose the task that is easy to develop objectively. There are many questions existing in teaching practice, but not all the questions can be the task of research. The pointing of some questions is very broad, they have large universality, the settle of those questions require more time and larger investment. As to a general teacher, limited by personal quality and objective research conditions, they do not have ability to afford. Other questions are too concrete, they are lacking of the value of universally popularizing. Therefore, we should take all conditions into consideration, to find out those tasks which are not only necessary and original but also are possible to research.

\section{How to accumulate the practice material: teaching is researching}

Writing teaching paper is a creative procedure with plan and purpose, it requires a long term accumulation of practice, it is not forced to write because of a sudden feeling or the applying for prize or position. Writing geography teaching paper in fact is a part that doing a teaching reform test and gain the result. Firstly we should connect writing geography teaching paper with daily teaching closely. "Teaching is researching", practicing repeatedly according to the chosen tasks, and collecting data successful experience in the practice, forming the written material and accumulating them in time. Second, developing the habit of taking notes, pay attention to collecting advanced theory, state of the field, information of typical examples concerning.

\section{How to write a paper with high quality}

We will take two articles concerning enforce training of the basic skills of the map for example, do some comparison and analysis.

The title of one is how to develop students' basic skills of reading and using map. The author firstly use two paragraphs to tell the importance of map in geography teaching briefly, then it get the point, saying: the article will state experiences on how to develop students' basic skills of reading and using map." The experience the article referred to mainly have there points: first, make students master general methods of reading a map on the basis of 
reading a map, and it especially refers to four skills that students should master, they are making directions, measuring distance, discriminating height and recognizing signs. Secondly, on the process of understanding the map, cultivating students' skills of reading and using maps. As for this question, the article just gives a few explanations to state the importance of doing so but not describes how to improve students' skills of reading and using maps in the process of understanding maps. Third, improving students' skills of reading and using maps through drawing maps, it introduces methods of leading students to carry on the plotting practice and drawing maps practice.

The other article's title is how to cultivate students' skills of reading, drawing and analyzing maps in geography teaching. The contents of the article can be divided into four parts: first, the research purpose; second, the research target and method; third, skill indicators and training methods; fourth, research results and experience.

Referring to the purpose of research, the article first describes the importance of maps in geography teaching, then it combines the questions existed in present teaching, raising up the purpose of the article: carry on the training of reading, drawing and analyzing maps in classes according to different grades, different teaching materials and different periods, encouraging students' observation, imagination and thinking ability, cultivating students' skills of interpretation, reasoning and analyzing, improving their skills of reading and using maps gradually, cultivating their skill of independently acquiring new knowledge from maps to a largest extent.

As for research object and methods, the article points out briefly, the research objects are junior students from grade one, grade two and senior one, total number is 150 . The main research methods are observation and investigation (quiz investigation and visiting investigation) as well as test. In the part of skill indicators and training methods, the article describe the skill indicators and training methods of map training in junior and senior. The indicators in junior period are: firstly, know the basic knowledge of map, learn to make direction, read rate, measure distance, discriminate heights, recognize signs, fill in notes, and draw slops and so on. Secondly, preliminarily learn to study the location of everywhere through reading maps, including latitude, land and sea location and adjacent areas. Thirdly, learn on the map to determine geographical traits, distribution and geographical traits it reflects. Fourthly, through reading the contents of different maps, analyzing the mutual links and mutual influences of geographical elements and the simple cause of geographical stuff. Fifthly, having the abilities of simply drawing outline map, distribution map and sketch map. Training methods can adopt drawing paintings, reading various maps and drawing simple maps and so on. The indicators in senior period are: firstly, having the basic ability of understanding, analyzing and using geographic concepts through reading maps. Secondly, learn to acknowledge geographical distribution, evolution and understand its rules through maps. Thirdly, learn to analysis connection of different elements, describe geographical features and cause contrastively. Fourthly, having the ability of evaluating a geographical stuff preliminarily through analyzing maps. Fifthly, learn to draw simple maps, sketch maps, mode chart, and simple geographic statistics charts. Training methods can adopt analysis of reading maps, evaluation of reading maps and understand of drawing maps.

In the part of research result and experience, the article first use statistics chart, comparing the final exam grades between testing class through one year training and control class, and gives analysis. Finally, the article summarizes some experiences: firstly, the training of reading, drawing and analyzing maps should pay attention to purpose, enforcing planning. Secondly, the training of reading, drawing and analyzing maps should pay attention to standardization and ordering. Thirdly, the training of reading, drawing and analyzing maps should pay attention to developing students' observation, imagination, thinking ability, cultivating their analyzing, judging, reasoning and complicate skills.

From content and introduction of the two articles, they are both teaching papers that have close contents, but the qualities of them are far away. The main differences between them are: the first is the pertinence of the article. The pertinence of the former article is not strong enough, it just briefly introduces the concrete actions according to the importance of map in teaching geography, but it does not take concrete actions according to practical questions existed in geography teaching. The latter one is different from that, it bases on the concrete questions that students have in mastering map skills discovered in teaching, then puts forward research task, makes concrete targets, and adopt corresponding actions, it certainly gains a better result. So it can be concluded that, the pertinence of task is not strong is important prerequisite that directly influences the purpose of paper and the result of paper. The second is the practice of teaching reform and planning are at different levels. The teaching reform the former one describes is lack of gradation due to the weak pertinence of the task, the indefinite purpose of task, the unspecific arrangement and the lack of planning. The latter one makes ability goals at different levels according to various conditions of senior students and questions existed, the purpose is definite, the measures to achieve these goals and methods that can be carried out are also concrete, the planning is strong. The third is the different analysis of teaching reform effectiveness. The former article just emphasizes the importance and methods of reforming map teaching, but it lack of examine and analysis of the research result, so it is not convincing. The latter article pays attention to the exam 
and analysis of experiment results; it has a qualitative analysis as well as detailed quantitative comparative analysis, so it has a strong force.

To sump up, the essential difference of the two articles are: the first one basically belongs to documentary article of teaching reform test practice, it lack of instruction of modern education theory and modern geography education principle, it necessarily analysis and improves teaching reform test experience, strictly speaking, it can not be a teaching geography paper, but a summary of geography teaching experience. The latter article is a typical teaching geography reform test paper, it gives definite description on the raising up of questions, the theory basis of teaching reform test, the levels of teaching reform, the contents, the methods and procedures of the teaching reform test, the result and experience of the teaching reform test. Therefore, this is a article that describes the results of geography teaching reform at two levels. Certainly, drawing such a conclusion does not mean that the latter article is perfect. In the analyzing part of the teaching reform, basically it still belongs to the nature of debating things according to facts; it is lack of necessary improvement on the basis of present map teaching and present map teaching reform, if we further strengthen the scientific analysis in experimental method and effect, emphasize those experience and thoughts that have universal meanings, and improve them to reach the height of modern teaching theory and modern geography teaching, then we can write geography teaching and education paper with a high quality.

\section{Conclusion}

Through the comparison and analysis of the two articles above, it is not difficult to draw a conclusion, that the geography teaching paper in fact is the results of geography teaching reform experiment research, it is under the instruction of scientific education theory and modern geography education principle, through reiterative geography teaching reform practice, experimenting and exploring basic theory question and practical question in teaching geography, and summarizing its universality rules scientifically. The teaching paper in high quality should be significant and it always focuses on some topic with proper research methods. Teaching reform practice in these high-quality papers always is well planned and organized. The authors always analyze the research question qualitatively and quantitatively to explore the results deeply being very typical and gaining theory from common law. These high-quality teaching papers are significant to teaching research.

\section{References}

Guo, Zhengquan. (1998). The Geography of the Modern School Teaching and Research, Beijing Huayi Press.

Li, Bingde. (2001). The Education Sciences Research Methods, the Education Press.

Pei, Xinsheng. (2002). The Creation of Thoughts and Practice in Geography Education, Beijing Science and Technology Press.

Yan, Xianyuan. (2002). The Implementation and Reform of the Course, Sichuan University Press.

http://www.5iread.com 